\title{
Perancangan Strategis Sistem Informasi Pada Stikom Artha Buana Kupang NTT
}

\author{
Information System Strategic Planning At Stikom Artha Buana Kupang NTT
}

\author{
Jimi Asmara ${ }^{1}$, Wing Wahyu Winarno ${ }^{2}$, Henderi $^{3}$ \\ ${ }_{1,2,3}$ Magister Teknik Informatika Universitas AMIKOM Yogyakarta \\ e-mail: ${ }^{1}$ jimmyasmara26@gmail.com, ${ }^{2}$ wingwahyuwinarno@gmail.com , \\ henderi@mail.ugm.ac.id
}

\begin{abstract}
Abstrak
STIKOM Artha Buana Kupang didirikan pada tanggal 2 Maret 2005 dengan misi, menghasilkan lulusan yang kreatif dan inovatif terhadap perkembangan teknologi informasi serta berbudi pekerti luhur, menghasilkan lulusan yang mampu menciptakan lapangan kerja serta mampu bersaing, mengembangkan STIKOM Artha Buana Kupang sebagai pusat Pendidikan, Penelitian, Pengabdian untuk Pengembangan IT khususnya di Nusa Tenggara Timur. STIKOM Artha Buana Kupang merupakan perguruan tinggi yang sudah menerapkan sistem informasi dalam pengelolaannya,namu sistem informasi tersebut belum maksimal dalam mencapai keunggulan kompetitif. Sistem informasi yang ada digunakan untuk mengelola data dan belum maksimal digunakan sebagai alat strategis, oleh karena itu diperlukan perancangan strategis sistem informasi. Pembuatan perancangan strategis sistem informasi pada paper ini menggukan dua framework yaitu ward and peppard dan information engineering, analisis yang dilakukan dengan metode value chain, SWOT, PEST, five force factor dan mcfarlan grid. Setalah dilakukan analisis internal dan eksternal menghasilkan rancangan strategis sistem informasi dan portofolio sistem informasi dan yang terakhir adalah penyususnan roadmap penerapan sistem informasi untuk lima tahun kedepan berdasarkan hasil focus group discussion dan mcfarlan grid.
\end{abstract}

Kata kunci--perancangan strategis sistem informasi, ward and peppard, information engineering.

\begin{abstract}
STIKOM Artha Buana Kupang was established on March 2, 2005 with a mission, produces creative and innovative graduates on the development of information technology and character, produces graduates who are able to create jobs and compete, develop STIKOM Artha Buana Kupang as a center of Education, Research, Devotion to IT Development especially in East Nusa Tenggara.STIKOM Artha Buana Kupang is a college that has implemented information systems in its management, information system is not maximized in achieving competitive advantage. Existing information systems are used to manage data and not maximally used as a strategic tool, therefore required strategic planning of information systems. The strategic planning information system in this paper is two framework namely ward and peppard and information engineering, analysis is done by value chain, SWOT, PEST, five force factor and mcfarlan grid. After internal and external analyzes have resulted in the strategic design of information systems and information systems portfolios and the last is the roadmap of information system implementation for the next five years based on focus group discussion and mcfarlan grid results.
\end{abstract}

Keywords--strategic planning information system, ward and peppard, information engineering. 


\section{PENDAHULUAN}

Perguruan tinggi memiliki peran yang besar dalam pembangunan bangsa melalui fungsi transformasi sumber daya manusia, ilmu pengetahuan, teknologi dan Sosial, perguruan tinggi menempati posisi yang strategis dalam perubahan masyarakat. Oleh karena itu perguruan tinggi, termasuk STIKOM Artha Buana Kupang harus mampu menjawab tantangan masa depan tersebut, dengan melaksanakan peran yang sebaik-baiknya agar upaya yang akan dilakukan untuk kurun waktu sepuluh tahun mendatang sesuai dengan kondisi lembaga dan akurat, maka perlu memperhatikan wawasan sejarah (masa lalu), masa kini, dan masa yang akan datang.

Perancangan strategis sistem dan teknologi informasi dibutuhkan untuk mempersiapkan organisasi dalam merencanakan pemakaian teknologi dan sistem informasi untuk organisasinya. Perancangan tersebut dibutuhkan untuk menyesuaikan gerak langkah organisasi dengan sistem informasi agar seirama dengan perkembangan organisasi untuk memenuhi kebutuhan sistem informasi organisasi di masa yang akan datang [1].

Sekolah Tinggi Informatika Komputer (STIKOM) Artha Buana Kupang didirikan pada tahun 2005, dan proses pembentukannya berdasarkan : Akte Notaris Silvester J. Mambaitfeta, SH Nomor : 7 , Tanggal 1 April 2000 tentang pendirian Yayasan Gemma Galgani. Sesuai dengan Akte Notaris Akte Notaris Zantje Mathilda Voss-Tomasowa, SH., M.kn Nomor 27, tanggal 8 November 2010 tentang Akta Pendirian Yayasan Soekarto. Akta Notaris Zantje Mathilda Voss-Tomasowa, SH., M.kn Nomor 23, tanggal 12 Januari 2011 tentang pelimpahan wewenang Hak Penyelenggaraan dan Kelola Sekolah Tinggi Informatika KomputerArtha Buana Kupang - Nusa Tenggara Timur. Dengan visi Menjadi perguruan tinggi yang berbasiskan Teknologi Informasi dengan mengedepankan pengetahuan (knowledge), skill (keterampilan) dan positif karakter (Berbudi Luhur), dan misi (a) Menghasilkan lulusan yang kreatif dan inovatif terhadap perkembangan teknologi informasi serta berbudi pekerti luhur, (b) Menghasilkan lulusan yang mampu menciptakan lapangan kerja serta mampu bersaing, (c) Mengembangkan STIKOM Artha Buana Kupang sebagai pusat Pendidikan Penelitian, Pengabdian untuk pengembangan IT.

Perancangan strategis sistem informasi pada STIKOM Artha Buana Kupang ini dapat mendukung proses bisnis kedepannya. Dengan adanya penerapan sistem informasi akan memberikan nilai lebih yang sesuai dengan visi misi dan tujuan dari organisasi, pada perancangan strategis sistem informasi ini juga disesuaikan dengan kondisi internal dan eksternal organisasi.

Berdasarkan latar belakang yang telah diuraikan tersebut maka diperoleh rumusan masalah yaitu (a) Seperti apa rancangan strategis sistem informasi pada STIKOM Artha Buana Kupang.?(b) Apasaja rekomendasi portofolio sistem informasi mendatang pada STIKOM Artha Buana Kupang.?

Adapun tujuan dari penelitian ini yaitu (a) Menghasilkan sebuah portofolio rancangan strategis sistem informasi pada STIKOM Artha Buana Kupang yang selaras dengan tujuan dan visi misi institusi dan organisasi, (b) Dapat menjadi panduan bagi institusi atau organisasi dalam menciptakan atau meningkatkan penggunaan sistem informasi, (c) Menghasilkan rancangan strategi sistem informasi untuk mencapai keunggulan kompetitif dalam bidang teknologi informasi dan sistem informasi pada STIKOM Artha Buana Kupang.

Beberapa penelitian terdahulu yang membahas tentang strategi sistem informasi. Penelitian yang dilakukan oleh [2] mencoba untuk mengimplementasikan sistem informasi untuk mengidentifikasi strategi dan teknologi apa yang akan digunakan sistem informasi tersebut sesuai dengan visi, misi serta kebutuhan Disnakertrans. Hasil dari perencanaan strategis sistem informasi Disnakertrans Provinsi Jawa Barat yang disusun dengan menggunakan Zachman Framework dengan metode Pereira dan Sousa dipetakan dalam bentuk tabel framework perancangan strategis sistem informasi Disnakertrans Provinsi Jawa Barat.

Penelitian yang dilakukan oleh [3] dilakukan di Desa Gadungan Puncu yang merupakan desa yang terletak di Kabupaten Kediri. Pada penelitian ini dibuat rencana strategis SI/TI untuk perkembangan teknologi sistem informasi terintegrasi dimana proses strategi dilakukan dalam 
beberapa tahap yaitu pemahaman kondisi saat ini dengan melakukan analisa internal desa dan analisa eksternal desa terkait dengan publikasi informasi dengan menggunakan SI/TI dilanjutkan dengan Analisa SWOT. Hasil akhir penelitian berupa portofolio aplikasi yang dibutuhkan untuk Desa Gadungan Puncu sebanyak tujuh aplikasi, empat diantaranya sudah dimiliki namun masih membutuhkan penyempurnaan agar dapat digunakan secara maksimal guna memenuhi kebutuhan bisnis dan dapat di integrasikan antara satu aplikasi dengan aplikasi lainnya.

Penelitian yang dilakukan oleh [4] menggunakan kombinasi Ward and Peppard dan EAP dan studi kasusnya pada organisasi pendidikan. Sekolah islam terpadu Salman Al Farisi Yogyakarta merupakan salah satu organisasi pendidikan formal yang sudah menerapkan sistem informasi dalam pengelolaannya. Pembuatan rencana strategis sistem informasi menggunakan kombinasi framework Ward and Peppard dan Enterprise Architecture Planning (EAP). Proses analisis menggunakan beberapa metode antara lain value chain, PEST, SWOT dan McFarland Strategic Grid. Setelah dilakukan analisis internal dan eksternal kemudian dirancang sebuah arsitektur data, arsitektur aplikasi dan arsitektur teknologi. Berdasarkan analisis dan arsitektur yang telah dilakukan akan menghasilkan strategi sistem informasi dan portofolio rekomendasi sistem informasi.

Penelitian lain dalam bidang strategis sistem informasi yang mendasari penelitian ini juga adalah [5], Bentuk perencanaan strategis sistem informasi yang dibahas dalam penelitian ini menggunakan metodologi Ward and Peppard dengan alat bantu metode analisis Value Chain untuk analisa lingkungan bisnis internal, Five Forces Model untuk analisa lingkungan bisnis eksternal, dan McFarlan Strategic Grid untuk analisa kondisi SI/TI internal saat ini. Hasil dari analisis ini mendefinisikan perencanaan strategis sistem informasi berupa strategi bisnis sistem informasi, strategi manajemen sistem informasi dan teknologi informasi, strategi sistem informasi, gap analisis sistem informasi, dan rencana implementasi.

Pada penelitian yang telah dilakukan terdahulu oleh peneliti lain menggunakan beberapa framework dan metode analisis yang bebeda. Penelitian Fardani dan Nalawati menggunakn Zachman Framework dengan metode Pereira dan Sousa, penelitian yang dilakukan oleh Sucipto dan Karaman menggunakan analisis SWOT, penelitian yang dilakukan oleh Widiati, Utami, Henderi dengan ward and peppard dan EAP, dan penelitian oleh Heriadi, Suyanto, Sudarmawan menggunakan metodologi Ward and Peppard, perdedaan dalam penelitian ini yaitu menggunakan metodologi ward and peppard dan information engineering.

Framework Ward and Peppard ini dimulai dari kondisi investasi SI/TI dimasa lalu yang kurang bermanfaat bagi tujuan bisnis organisasi dan menangkap peluang bisnis, serta fenomena meningkatkan keunggulan kompetitif suatu organisasi karena mampu memanfaatkan SI/TI dengan maksimal [6]. Framework Information Engineering merupakan sebuah pendekatan untuk perencanaan, analisis, dan implementasi suatu aplikasi dalam suatu perusahaan, yang bertujuan untuk memungkinkan suatu perusahaan untuk meningkatkan sumber dayanya termasuk modal, kualitas SDM dan Sistem Informasi [7].

\section{METODE PENELITIAN}

Framework yang digunakan dalam penelitian ini yaitu ward and peppard dan information engineering, pemilihan framework tersebut karena Ward \& Peppard pada awal kemunculannya memang diciptakan untuk fokus terhadap kebutuhan bisnis yang diseimbangkan dengan teknologi yang memang sangat diperlukan dan berguna bagi jalannya proses bisnis suatu organisasi. Information engineering dipilih karena metodologi ini memiliki kekuatan untuk meningkatkan kualitas SDM dan sumber daya sehingga dapat mendukung organisasi untuk bisa bersaing dan mencapai keunggulan kompetitif. Alur penelitian ditunjukkan pada gambar 1 berikut: 


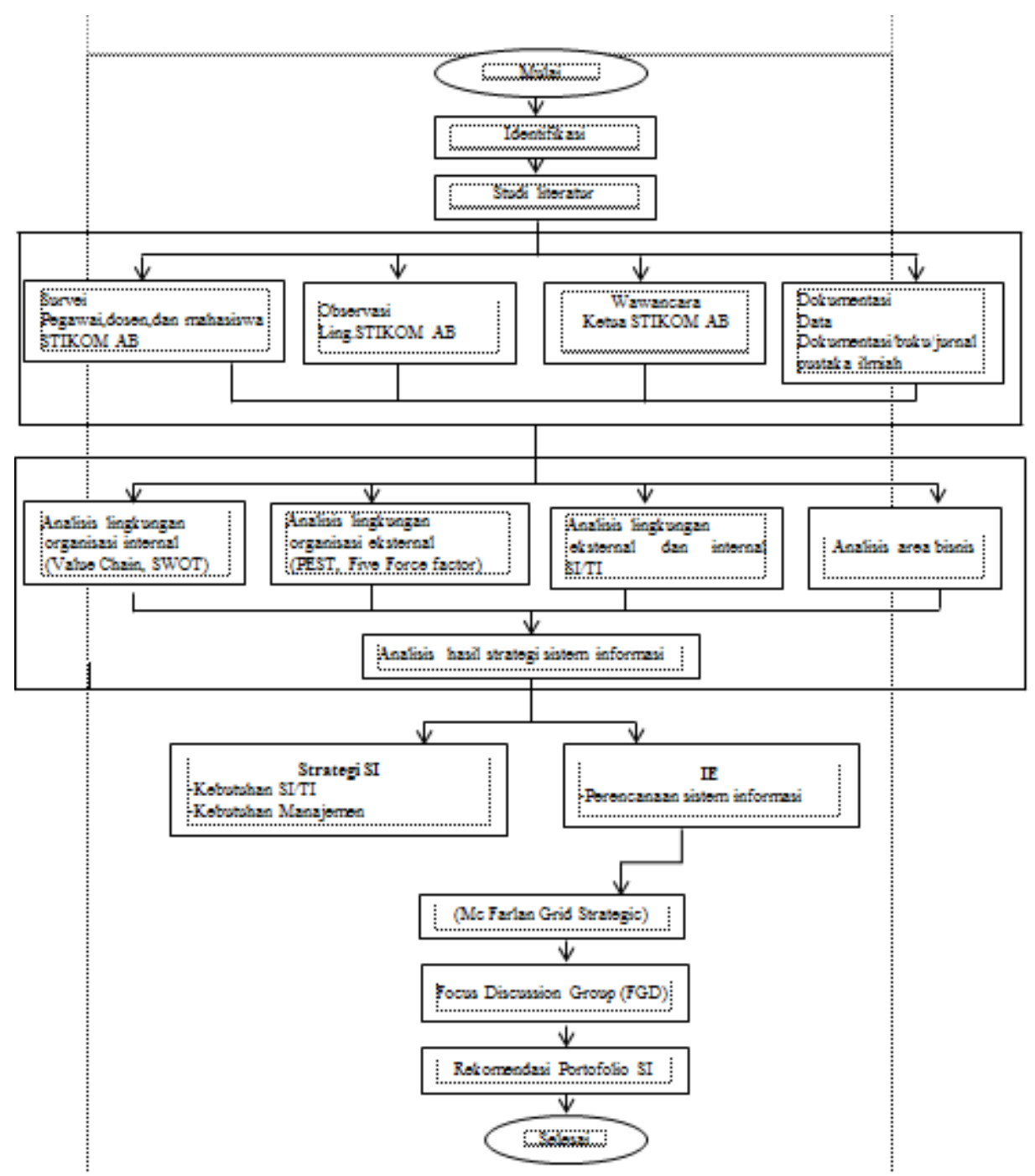

Gambar 1 Alur Penelitian

Keterangan

a. Survei dilakukan secara langsung kepada mahasiswa, pegawai, dosen untuk mengetahui kondisi kebutuhan manajemen, kebutuhan SI/TI dan proses bisnis serta rencana strategis pada STIKOM Artha Buana.

b. Wawancara dilakukan secara langsung kepada Ketua STIKOM Artha Buana, dosen dan pegawai untuk mengetahui visi misi yayasan, tujuan serta rencana strategi sistem informasi dan kebutuhan SI/TI dan kebutuhan manajemen.

c. Observasi dilakukan pada lingkungan kampus STIKOM Artha Buana meliputi mahasiswa, dosen dan pegawai untuk mengetahui proses bisnis yang berjalan dengan cara mengamati langsung obyek datanya.

d. Dokumentasi dilakukan untuk memperkuat data wawancara dan observasi dibutuhkan juga sejumlah data dokumentasi yakni data-data mengenai karyawan, dokumentasi aplikasi dan data pendukung lainnya pada STIKOM Artha Buana Kupang.

e. Studi literatur dilakukan untuk melengkapi data primer, sehingga mendapatkan teori yang relevan denga penelitian yang dilakukan. Referensi yang digunakan terkait dengan perencanaan strategis sistem informasi yang didapat dari buku dan jurnal ilmiah. Dari beberapa sumber pengumpulan data tersebut, apabila data masih dirasa kurang mencukupi maka akan diulang dan diambil data-data yang masih kurang untuk 
mendukung kebutuhan SI/TI, kebutuhan manajemen, proses bisnis, rencana strategi pada STIKOM Artha Buana Kupang.

Tahapan dalam analisis data yang akan dilakukan dalam penelitan sebagai berikut:

a. Melakukan analisis Value Chain, SWOT, PEST, Five Force, dan Mc Farlan Grid.

b. Melakukan analisis lingkungan eksternal yang mecakup aspek ekonomi, industri, dan iklim bersaing perusahaan. Lingkungan bisnis eksternal dapat memacu perusahaan untuk maju dan bersaing.

c. Melakukan analisis lingkungan SI/TI internal, yang mencakup kondisi SI/TI organisasi dari perspektif bisnis saat ini, bagaimana kematangan, bagaimana kontribusi terhadap bisnis, keterampilan sumber daya manusia, infrastruktur teknologi termasuk portofolio dari SI/TI yang ada saat ini.

d. Melakukan analisis lingkungan SI/TI eksternal yang mencakup trend teknologi dan peluang pemanfaatannya, serta pengguna SI/TI oleh kompetitor pelanggan dan pemasok. Analisis ini digunakan untuk mendapat pemahaman terhadap perkembangan SI/TI diluar organisasi yang dapat memberikan kelangsungan hidup terhadap organisasi.

e. Analisis Perencanaan Sistem Informasi. Analisis dan evaluasi terhadap hasil perencanaan sistem informasi dilakukan untuk menjamin bahwa semua fungsi dan entitas yang dibutuhkan sudah tercakup dalam perencanaan.

f. Melakukan analisis area bisnis, dimaksudkan untuk mencoba mengidentifikasi peluang bisnis yang perlu dengan segera mendapatkan perhatian eksekutif dan disaat yang sama diarahkan untuk mengetahui ancaman bisnis yang perlu mendapat antisipasi [8].

\section{HASIL DAN PEMBAHASAN}

Analisis lingkungan organisasi internal (Value Chain) Stikom Artha Buana Kupang

\begin{tabular}{|c|c|c|c|c|}
\hline \multirow{6}{*}{$\begin{array}{l}\text { Aktivitas } \\
\text { Pendukung }\end{array}$} & \multicolumn{4}{|c|}{ Pengelolaan teknologi } \\
\hline & \multicolumn{4}{|c|}{ Pengelolaan infrastruktur,sarana dan prasarana } \\
\hline & \multicolumn{4}{|c|}{ Pengelolaan perpustakaan } \\
\hline & \multicolumn{4}{|c|}{ Pengelolaan SPMI (Standar Penjamin Mutu Internal) } \\
\hline & \multicolumn{4}{|c|}{ Pengelolaan SDM } \\
\hline & \multicolumn{4}{|c|}{ Pengelolaan kegiatan ekstrakurikuler mahasiswa } \\
\hline $\begin{array}{l}\text { Aktivitas } \\
\text { Utama }\end{array}$ & $\begin{array}{l}\text { PMB dan } \\
\text { kurikulum }\end{array}$ & $\begin{array}{l}\text { Penelitian dan } \\
\text { pengabdian } \\
\text { masyarakat }\end{array}$ & $\begin{array}{l}\text { Kerjasama } \\
\text { antar instansi } \\
\text { dan } \\
\text { usaha }\end{array}$ & $\begin{array}{l}\text { Alumni, } \\
\text { promosi dan } \\
\text { pemasaran }\end{array}$ \\
\hline
\end{tabular}

Gambar 2 Analisis Value Chain

Gambar 2 menunjukkan hasil analisis dengan menggunakan metode analisis Value Chain STIKOM Artha Buana Kupang. Value Chain terdiri dari dua aktivitas yaitu aktivitas utama dan aktivitas pendukung. Aktivitas utama terdiri dari penerimaan siswa baru dan kurikulum, penelitian dan pengabdian masyarakat, kerjasama antar instansi,alumni, promosi dan pemasaran. Aktivitas pendukung terdiri pengelolaan teknologi, pengelolaan infrastruktur,saran dan prasarana, pengelolaan perpustakaan,pengeloaan SPMI, SDM dan pengelolalaan ekstrakurikuler mahasiswa.

\section{Analisis SWOT lingkungan organisasi internal}

Analisis SWOT ini merupakan analisis yang terdiri dari Strength atau kekuatan organisasi, Weakness atau kelemahan organisasi, Opportunity atau peluang dan Threat atau ancaman organisasi. 
Tabel 1. Analisis SWOT pada STIKOM Artha Buana Kupang NTT.

\begin{tabular}{|c|c|}
\hline Strength & Weaknees \\
\hline $\begin{array}{l}\text { 1. Adanya visi, misi yang dapat dimengerti dan } \\
\text { dijadikan dasar pijak dalam kebijakan } \\
\text { akademik untuk percapaian Tri Dharma } \\
\text { perguruan Tinggi. } \\
\text { 2. Adanya penataan organisasi dan tata kerja di } \\
\text { tingkat program studi maupun unit atau sub } \\
\text { unit kerja yang didasarkan pada manajemen } \\
\text { mutu terpadu } \\
\text { 3. Kepercayaan publik terhadap STIKOM Artha } \\
\text { Buana dan output yang dihasilkannya. } \\
\text { 4.Setiap mahasiswa selalu melakukan } \\
\text { bimbingan secara rutin dan layanan } \\
\text { pembimbingan sangat interaktif sertai } \\
\text { mahasiswa mengikuti kegiatan dan berbagai } \\
\text { komisi dan ektrakurikuler sangat efektif } \\
\text { 5. Adanya sumber pemasukan dana baik dari } \\
\text { biaya sumbangan pendidikan mampu } \\
\text { menunjang kebutuhan dan operasional kerja } \\
\text { secara baik. } \\
\text { 5. Tersedianya fasilitas berupa gedung, ruang } \\
\text { kuliah, laboratorium, perpustakaan, sistem } \\
\text { informasi dan fasilitas parkir yang memadai } \\
\text { serta fasilitas pendukung lainnya untuk } \\
\text { kepentingan proses belajar mengajar. } \\
\text { 7. Secara rutin dilakukan kegiatan pengabdian } \\
\text { kepada masyarakat oleh dosen dan } \\
\text { mahasiswa dengan mengambil lokasi pada } \\
\text { tempat/daerah strategis sesuai dengan tujuan } \\
\text { dan manfaat } \\
\text { 3. Dilibatkannya pihak pemerintah dan swasta } \\
\text { untuk mendukung pelaksanaan pengabdian } \\
\text { masyarakat. }\end{array}$ & $\begin{array}{l}\text { 1. Lambat dalam pengurusan proses akreditasi. } \\
\text { 2. Masih kurangnya dosen berkualifikasi } \\
\text { magister dan doktor di bidang komputer. } \\
\text { 3. Kurangnya minat dosen dalam melakukan } \\
\text { penelitian-penelitian baru } \\
\text { 4. Kurangnya publikasi dan minat untuk } \\
\text { melakukan dan membaca hasil penelitian } \\
\text { dosen dan mahasiswa sehingga } \\
\text { manfaat/kontribusi hasil penelitian belum } \\
\text { secara optimal. }\end{array}$ \\
\hline Opportunity & Threat \\
\hline $\begin{array}{l}\text { 1. Melakukan kerjasama dengan } \\
\text { lembaga/instansi terkait sehingga dapat } \\
\text { membuka program dan produk-produk baru } \\
\text { dalam rangka ekspansi dan diversifikasi } \\
\text { produk. } \\
\text { 2. Adanya upaya meningkatkan pengetahuan } \\
\text { dan kemampuan manajemen staf akademik } \\
\text { dan administrasi sesuai tuntutan dan } \\
\text { perkembangan organisasi. } \\
\text { 3. Adanya dukungan pemerintah provinsi NTT } \\
\text { dalam hal pengembangan IT diwilayah NTT } \\
\text { khususnya kota kupang } \\
\text { 4. Dengan transparannya sistem pengelolaan } \\
\text { dana maka akan mampu meningkatkan }\end{array}$ & $\begin{array}{l}\text { 1. Pertumbuhan dan Perkembangan IPTEK } \\
\text { yang signifikan, menuntut penyesuaian } \\
\text { kurikulum terhadap kebutuhan pasar } \\
\text { 2. Persaingan Perguruan Tinggi yang sejenis. } \\
\text { 3. Belum siapnya kemampuan dan keahlian } \\
\text { SDM dalam pengelolaan sistem informasi } \\
\text { secara tepat guna mengakibatkan selalu } \\
\text { terlambat dalam mendapatkan informasi } \\
\text { perubahan dan perkembangan Iptek untuk } \\
\text { kepentingan proses belajar mengajar di } \\
\text { Program Studi. }\end{array}$ \\
\hline
\end{tabular}




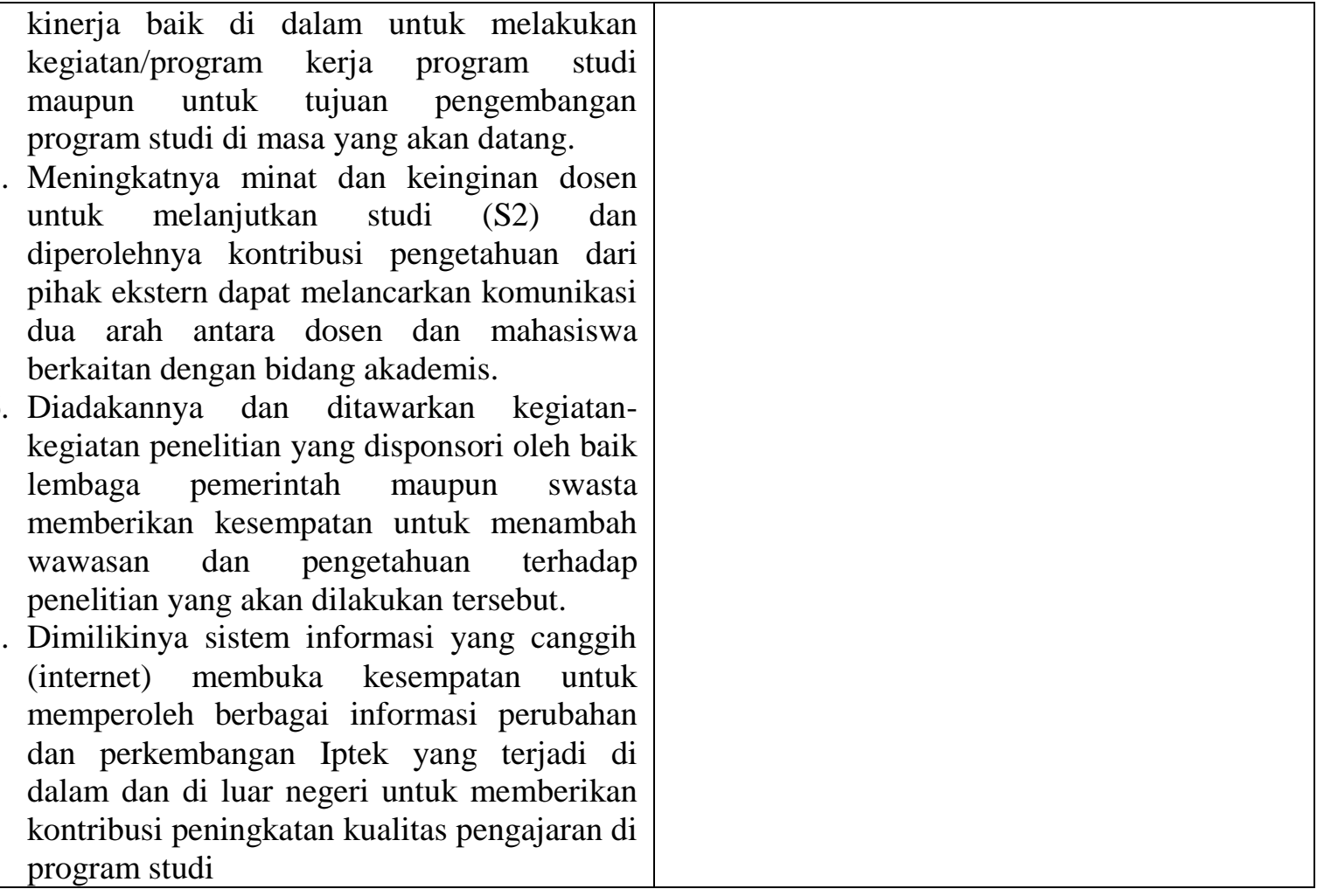

Berdasarkan hasil analisis SWOT yang ditunjukan pada tabel 1 terdiri dari delapan kekuatan (strength), empat kelemahan (weaknees), tujuh peluang (opportunities), dan tiga ancaman (threats) sehingga bisa digunakan dalam penetuan sistem informasi mendatang yang dibutuhkan oleh STIKOM Artha Buana Kupang

\section{Analisis Lingkungan Organisasi Eksternal (PEST analisis)}

Lingkungan organisasi ekternal sangat mempengaruhi proses dari organisasi STIKOM Artha Buana kupang, proses dari pengaruh lingkungan eksternal cukup memiliki dampak terdahap STIKOM Artha Buana Kupang dalam hal proses penerimaan mahasiswa baru. Untuk menganalisis organisasi ekternal digunakan model analisis PEST (Politik, Ekonomi, Sosial dan Teknologi. 
Tabel 2 Analsis Pest

\begin{tabular}{|c|c|}
\hline Politik & Ekonomi \\
\hline $\begin{array}{l}\text { 1. Undang-undang republik indonesia } \\
\text { Nomor } 12 \text { tahun } 2012 \text { Tentang } \\
\text { Pendidikan tinggi } \\
\text { 2. Peraturan pemerintah republik } \\
\text { indonesia Nomor } 4 \text { tahun } 2014 \\
\text { Tentang Penyelenggaraan pendidikan } \\
\text { tinggi dan pengelolaan perguruan } \\
\text { tinggi } \\
\text { 3. Peraturan Menteri pendidikan dan } \\
\text { kebudayaan Republik indonesia } \\
\text { Nomor } 95 \text { tahun } 2014 \text { Tentang } \\
\text { Pendirian, perubahan, dan } \\
\text { pembubaran Perguruan tinggi negeri } \\
\text { serta pendirian, perubahan, dan } \\
\text { pencabutan izin perguruan tinggi } \\
\text { swasta }\end{array}$ & $\begin{array}{l}\text { 1. Kondisi ekonomi masyarakat indonesia } \\
\text { khususnya di Nusa Tengga Timur, yang } \\
\text { berprofesi sebagai petani dan nelayan } \\
\text { mempengaruhi minat orang tua untuk } \\
\text { melanjutkan pendidikan anaknya } \\
\text { keperguruan tinggi. } \\
\text { 2. Tingkat pendapatan dari UMP (upah } \\
\text { minimum provinsi) dirasakan belum } \\
\text { mencukupi untuk membiayayai } \\
\text { pendidikan pada perguruan tinggi. } \\
\text { 3. Tingkat suku bunga standar nilai tukar } \\
\text { dan tingkat inflasi harga produk barang } \\
\text { dan jasa }\end{array}$ \\
\hline Sosial & Teknologi \\
\hline $\begin{array}{l}\text { 1. Gaya hidup masyarakat yang NTT } \\
\text { masih kental dengan adat dan budaya. } \\
\text { 2. Pendidikan yang tinggi belum } \\
\text { manjadi prioritas utama masyarakat } \\
\text { NTT } \\
\text { 3. Keselamatan dan kesejahteraan social }\end{array}$ & $\begin{array}{l}\text { 1.Sudah diterapkan sistem informasi pada } \\
\text { perguruan tinggi. } \\
\text { 2.Layanan mobile, jaringan internet, } \\
\text { jaringan komputer sudah cukup dirasakan } \\
\text { oleh masyarakat NTT } \\
\text { 3.Aktivitas penelitian dan pengembangan } \\
\text { teknologi di NTT }\end{array}$ \\
\hline
\end{tabular}

Tabel 2 menjelaskan tentang analisis lingkungan eksternal STIKOM Artha Buana Kupang dapat dilihat dari empat komponen yaitu, politik, ekonomi, sosial dan teknologi, dari hasil analisis PEST tersebut diatas kondisi ekonomi dan sosial yang berpengaruh terhadap STIKOM Artha Buana Kupang, hal ini karenakan kondisi ekonomi masyarakat Nusa Tenggara Timur yang sebagian besar petani dan nelayan sehingga mempengaruhi minat untuk melanjutkan pendidikan ke perguruan tinggi. Sedangkan dari aspek sosialnya pola hidup masyarakat Nusa Tengara Timur yang masih kental dangan adat budaya sehingga prioritas pendidikan yang tinggi bukan pilihan utama.

\section{Analisis Lingkungan Organisasi Eksternal (Five Force factor)}

Model analasis five force factor di perlukan untuk menentukan posisi STIKOM Artha Buana Kupang pada kondisi eksternal yang akan mempengaruhi kegiatan bisnis organisasi STIKOM Artha Buana Kupang. 


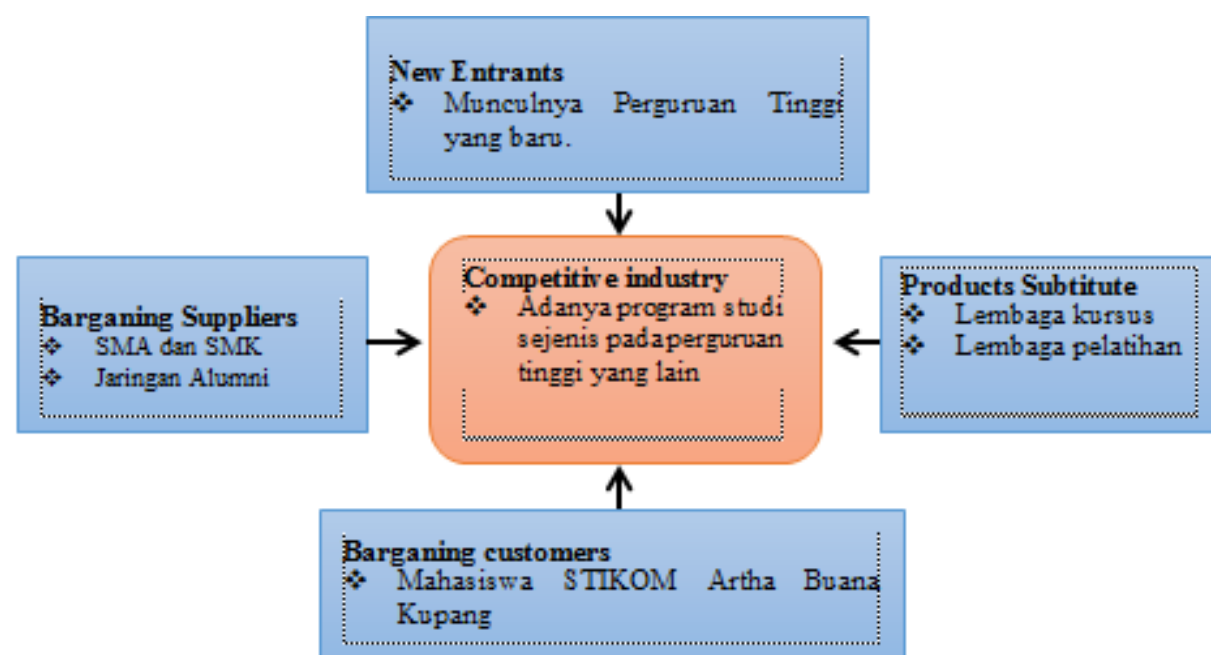

Gambar 3 Five Force Factor

Uraian dari analisis five force factor adalah sebagai berikut:

a. Competitive rivalry within an industry

Pesaing utama bisnis organisasi adalah dari perguruan tinggi yang sejenis pada saat ini STIKOM Artha Buana Kupang mempunyai pesaing khususnya di kota kupang adalah Universitas Widya Mandira Kupang, STIKOM Uyelindo Kupang dan STIM Kupang.

b. Berganing power of customers

Pelayanan terhadap konsumen dalam hal ini adalah mahasiswa dari STIKOM Artha Buana sendiri adalah hal yang paling penting bagi STIKOM Artha Buana sendiri dimana dengan adanya pelayanan yang membuat mahasiswa nyaman dan bisa mempromosikan STIKOM Artha Buana kepada calon mahasiswa baru untuk mendukung perkembangan dan kemajuan STIKOM Artha Buana.

c. Bargaining power of supplier

Jumlah mahasiswa yang masuk pada STIKOM Artha Buana harus menyesuaikan dengan jumlah tenaga pengajar yang ada serta sarana dan fasilitas yang ada untuk menunjang kegiatan belajar dan mengajar seperti ruang kuliah, ruang praktek. Sehingga tidak terjadi kondisi dimana jumlah mahasiswa lebih banyak dari pada tenaga pengajarnya.

d. Threats of new entrants

Selalu meningkatkan kualitas mutu pelayanan baik internal dan eksternal untuk mengahadapi persaingan dengan perguruan tinggi yang sejenis yang ada di kota kupang.

e. Threats of subtitute

Dengan adanya perguruan tinggi sejenis di kota kupang maka STIKOM Artha Buana Kupang harus terus meningkatkan fasilitas pendukung kegiatan belajar mengajar terutama pada teknologi infomasi dan komputernya, STIKOM Artha Buana kupang dalam hal ini tidak hanya bersaing dengan sesama perguruan tinggi tetapi juga dengan berbagai lembaga kursus, lembaga pelatihan dan sebagainya dapat menjadi ancaman dalam persaingan bisnis organisasi.

\section{Analisis Lingkungan Internal SI/TI}

a. Pembahasan terhadap has Perangkat Keras (Hardware)

b. Perangkat Lunak (Software)

c. Sistem Operasi

d. Infrastruktur Untuk mendukung proses belajar mengajar dan pelayanan kepada mahasiswa. 


\section{Analisis Lingkungan Eksternal SI/TI}

Analisis lingkungan Eksternal dalam hal ini penulis melihat dari perkembangan teknologi yang akan terjadi tahun 2017 di Indonesia, yang terdiri dari AI dan Advanced Machine Learning, Intelligent Apps, Intelligent Things, VR dan AR, Digital Twins, blockchain, conversational system, Mesh App and Service Architecture, Digital Technology Platforms, Adaptive Security Architecture[9].

\section{Analisis Area Bisnis}

Penentuan strategi bisnis diawali, Membuka peluang bisnis di lingkungan kota kupang, misalnya untuk pembuatan sistem informasi apapun di lingkungan instansi pemerintah dan swasta menyediakan fasilitas wifi untuk meningkatkan efektifitas dan membangun strategi pemasaran produk-produk misalnya hardware, software atau brainware yang di hasilkan oleh STIKOM Artha Buana Kupang. Area pelatihan dan pengembangan SDM instansi pemerintah maupun swasta yang ada di kota kupang, mengadakan jobfair untuk menyediakan informasi lowongan pekerjaan dan menjalin komunikasi antara STIKOM Artha Buana Kupang dengan stackholder yang menyediakan fasilitas untuk kelanjutan alumni.

\section{Information Engineering}

Perencanaan sistem informasi dalam metodologi Information Engineering dapat dibagi ke dalam dua bagian. Bagian pertama berhubungan dengan tinjauan strategis atas informasi yang dibutuhkan untuk mengoperasikan enterprise secara efektif, bagian kedua berfokus pada pemanfaatan teknologi untuk meningkatkan kenerja enterprise.

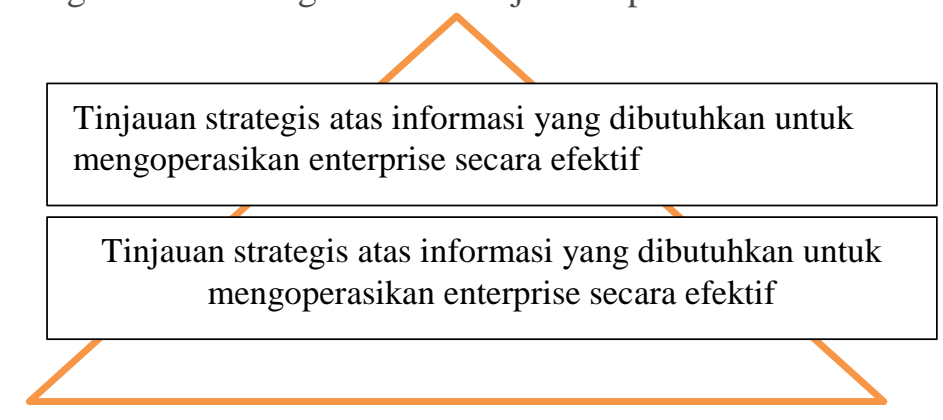

Gambar 4 Dua bagian perencanaan sistem informasi

Tinjauan strategis atas informasi yang dibutuhkan untuk mengoperasikan enterprise secara efektif untuk suatu organisasi bisa melakukan suatu kegiatan dengan bantuan sistem informasi guna mencapai suatu keunggulan kompetitif dan Pemanfaatan teknologi untuk meningkatkan kinerja enterprise dalam hal ini manajemen menggunakan sistem informasi yang dibangun atau dikembangkan untuk membantu meningkatkan kualitas pelayanan dan mewujudkan visi misi dan tujuan sehingga keunggulan kompetitif bisa tercapai.

\section{Rancangan Strategis Sistem Informasi}

Rancangan strategis sistem informasi pada gambar 5 yang akan menempati posisi strategis yakni sistem informasi tersebut dapat mengubah organisasi dalam bisnis dan berpotensi menyediakan keunggulan kompetitif. Sistem informasi yang sudah ada saat ini semuanya masih menjadi sistem informasi operasional. Maka dari itu dengan adanya usulan sistem informasi yang berada pada posisi strategis akan dapat menjadi solusi sistem informasi dalam mewujudkan keunggulan kompetitif. 


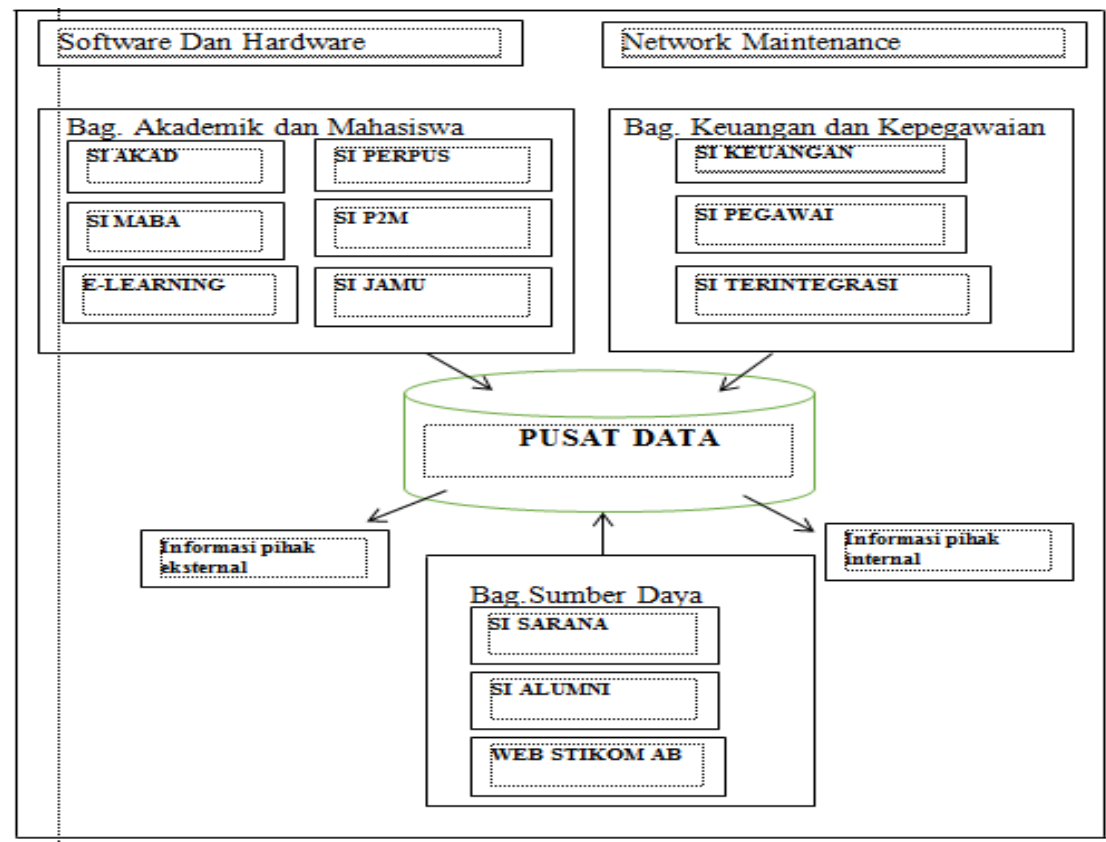

Gambar 5 Rancangan Strategis Sistem Informasi

\section{Kebutuhan SI/TI yang akan datang pada STIKOM Artha Buana Kupang}

Dari hasil analisis lingkungan internal organisasi value chain dan SWOT yang telah dilakukan maka didapatkan solusi kebutuhan sistem informasi, kebutuhan SI/TI untuk STIKOM Artha Buana Kupang seperti yang tampak pada tabel tabel 3.

Tabel 3 Kebutuhan SI/TI

\begin{tabular}{|l|l|l|}
\hline No & Kebutuhan SI/TI & Solusi SI/TI \\
\hline 1 & $\begin{array}{l}\text { Sistem informasi yang dapat mengelola seluruh } \\
\text { aktivitas penerimaan mahasiswa baru,Sistem ini } \\
\text { harus terhubung dengan aktivitas promosi dan } \\
\text { pendidikan }\end{array}$ & SI MABA \\
\hline 2 & $\begin{array}{l}\text { Sistem informasi yang akan mempermudah proses } \\
\text { belajar mengajar dan bimbingan }\end{array}$ & e-learning \\
\hline 3 & $\begin{array}{l}\text { Sistem informasi yang dapat mengelola kegiatan } \\
\text { penelitian dan pengabdian masyarakat dan teknologi } \\
\text { informasi }\end{array}$ & SI P2M dan TI \\
\hline 4 & $\begin{array}{l}\text { Sistem informasi yang dapat mengelola mahasiswa } \\
\text { dan alumni dan ekstrakurikuler. }\end{array}$ & SI alumni \\
\hline 5 & $\begin{array}{l}\text { Sistem informasi yang dapat mengelola kegiatan } \\
\text { akademik }\end{array}$ & Sistem informasi akademik \\
\hline 6 & $\begin{array}{l}\text { Sistem informasi yang dapat mengelola transaksi } \\
\text { keuangan }\end{array}$ & Sistem informasi keuangan \\
\hline 7 & $\begin{array}{l}\text { Sistem informasi yang mengelola administrasi } \\
\text { perpustakaan dan koleksi buku }\end{array}$ & $\begin{array}{l}\text { Sistem informasi } \\
\text { perpustakaan }\end{array}$ \\
\hline 8 & $\begin{array}{l}\text { Sistem informasi yang dapat mengelola administrasi } \\
\text { kepegawaian dan SDM }\end{array}$ & $\begin{array}{l}\text { Sistem informasi } \\
\text { kepegawaian }\end{array}$ \\
\hline 9 & $\begin{array}{l}\text { Sistem informasi yang dapat mengelola kegiatan } \\
\text { pengadaan dan inventarisasi sarana prasarana }\end{array}$ & SI sarana prasarana \\
\hline 10 & $\begin{array}{l}\text { Sistem informasi yang dapat memberikan informasi } \\
\text { dan promosi mengenai profil STIKOM Artha Buana } \\
\text { Kupang. }\end{array}$ & $\begin{array}{l}\text { Website STIKOM Artha } \\
\text { Buana Kupang }\end{array}$ \\
\hline
\end{tabular}




\begin{tabular}{|l|l|l|}
\hline 11 & Sistem informasi penjaminan mutu internal & Si Jamu \\
\hline 12 & $\begin{array}{l}\text { Sistem manajemen informasi yang secara efektif } \\
\text { dapat didayagunakan untuk mendukung proses } \\
\text { pengumpulan data, analisis, penyimpanan, } \\
\text { pengunduhan, presentasi data dan informasi, dan } \\
\text { komunikasi dengan pihak berkepentingan. }\end{array}$ & SI terintegrasi \\
\hline
\end{tabular}

Berdasarkan tabel 3 diatas selanjutnya didapatkan gambaran aktivitas dan kebutuhan sistem informasi masa depan yang dapat mendukung peningkatan keunggulan bersaing pada STIKOM Artha Buana Kupang. Tabel 4 menunjukan aktivitas dan kebutuhan sistem informasi akan datang pada STIKOM Artha Buana Kupang.

Tabel 4 Aktivitas dan kebutuhan sistem informasi akan datang pada STIKOM Artha Buana Kupang

\begin{tabular}{|l|l|l|l|}
\hline No & Aktivitas & Sistem Informasi & Unit pengguna \\
\hline 1 & Pengadaan sarana dan prasaran & $\begin{array}{l}\text { SI sarana dan } \\
\text { prasana. }\end{array}$ & $\begin{array}{l}\text { BAU } \\
\text { UPT LAB. }\end{array}$ \\
\hline 2 & Pengelolaan SDM dan pegawai & SI PEG. & Kepegawaian. \\
\hline 3 & Pengelolaan keuangan & SI KEU & $\begin{array}{l}\text { BAAK } \\
\text { BAU }\end{array}$ \\
\hline 4 & $\begin{array}{l}\text { Pengelola mahasiswa dan alumni dan } \\
\text { ekstrakurikuler }\end{array}$ & SI Alumni & BAU \\
\hline 5 & Pengelola perpustakaan & SI Perpustakaan & UPT Perpustakaan. \\
\hline 6 & Pengelolaan akademik & SI Akad & BAK \\
\hline 7 & $\begin{array}{l}\text { Pengelolaan akademik dan } \\
\text { kurikulum }\end{array}$ & SI MABA & BAAK \\
\hline 8 & $\begin{array}{l}\text { Pengelolaan perkuliahan dan } \\
\text { bimbingan }\end{array}$ & e-learning & $\begin{array}{l}\text { BAAK } \\
\text { BAU } \\
\text { UPT LAB }\end{array}$ \\
\hline 9 & Pengabdian masyarakat dan peneltian & SI P2M & LP2M \\
\hline 10 & $\begin{array}{l}\text { Pengelola informasi pemasaran,iklan } \\
\text { dan promosi }\end{array}$ & $\begin{array}{l}\text { WEB } \\
\text { arthabuana.ac.id }\end{array}$ & Humas \\
\hline 11 & Penjaminan mutu internal & SI JAMU & LP2M \\
\hline 12 & $\begin{array}{l}\text { Mengelola penyimpanan, } \\
\text { pengunduhan, presentasi data dan } \\
\text { informasi, dan komunikasi dengan } \\
\text { pihak berkepentingan. }\end{array}$ & SI Terintegrasi & BAAK \\
\hline
\end{tabular}

Berdasarkan tabel 4 diperoleh 12 usulan sistem informasi mendatang. Sistem informasi tersebut akan dipetakan dengan menggunakan McFarland Strategic Grid. Tabel 5menunjukkan pemetaan usulan sistem informasi dengan menggunakan McFarland Strategic Grid.

Tabel 5 Future Application Portfolio McFarlan Grid Strategic.

\begin{tabular}{|l|l|}
\hline Strategic & High Potential \\
\hline SI AKAD** & WEB STIKOM Artha Buana Kupang** \\
SI Kepegawaian* & SI JAMU* \\
SI Keuangan* & SI Alumni* \\
SI P2M* & \\
E-Learning & \\
\hline
\end{tabular}




\begin{tabular}{|l|l|}
\hline Key Operational & Support \\
\hline SI PERPUS** & SI SARANA* \\
SI MABA* & SI Terintegrasi* \\
\hline
\end{tabular}

Ket: * sudah ada, $* *$ buat baru.

Sistem informasi yang sudah ada saat ini terdiri dari tiga yaitu si akad, si perpus dan website.dan yang direkomendasi untuk dibuat baru terdiri dari 9 sistem informasi. Oleh karena itu dengan adanya usulan sistem informasi dapat menjadi solusi sistem informasi dalam mewujudkan keunggulan kompetitif.

Dalam roadmap implementasi portofolio ini akan ditampilkan lama waktu pembangunan untuk masing - masing sistem informasi yang akan dibangun seperti yang tampak pada tabel 6 dibawah ini.

Tabel 6 Roadmap Implementasi.

\begin{tabular}{|l|l|l|l|l|l|l|}
\hline \multirow{2}{*}{ NO } & Sistem Informasi & \multicolumn{5}{|c|}{ Tahun } \\
\cline { 5 - 7 } & & 2017 & $\mathbf{2 0 1 8}$ & $\mathbf{2 0 1 9}$ & $\mathbf{2 0 2 0}$ & $\mathbf{2 0 2 1}$ \\
\hline $\mathbf{1}$ & SI KEUANGAN & & & & & \\
\hline $\mathbf{2}$ & SI AKAD & & & & & \\
\hline 3 & SI PERPUS & & & & \\
\hline $\mathbf{4}$ & WEB STIKOM AB & & & & & \\
\hline $\mathbf{5}$ & SI INTEGRASI & & & & & \\
\hline $\mathbf{6}$ & SI MABA & & & & & \\
\hline $\mathbf{7}$ & E- LEARNING & & & & & \\
\hline $\mathbf{8}$ & SI SARANA & & & & & \\
\hline 9 & SI KEPEGAWAIAN & & & & & \\
\hline 10 & SI P2M & & & & & \\
\hline 11 & SI JAMU & & & & & \\
\hline 12 & SI ALUMNI & & & & & \\
\hline
\end{tabular}

Berdasarkan tabel 6 di tahun 2017 akan dibangun tiga sistem informasi, tahun 2018 tiga sistem informasi, 2019 dua sistem informasi, 2020 dua sistem informasi, 2021 dua sistem informasi.

\section{KESIMPULAN}

Penggunaan dua metode Ward \& Peppard dan Information Engineering pada penelitian ini menghasilkan dua belas (12) rencana sistem informasi strategis yang sudah dipetakan dalam McFarlan Grid sehingga dapat membantu pihak manajemen untuk mencapai keunggulan kompetitif. Berdasarkan roadmap portofolio sistem informasi yang diperlukan, sebanyak dua belas (12) sistem informasi, harus dibuat baru ada sembilan (9) terdiri Si Kepegawaian, Si Keuangan, Si P2M, E-Learning, Si Maba, Si Sarana, Si Jamu Si Alumni, Si Terintegrasi. Sistem informasi yang sudah digunakan ada tiga (3) terdiri dari Si Akad, Si Perpus, dan Web STIKOM Artha Buana Kupang. Berdasarkan waktu rencana implementasi setidaknya diperlukan waktu lima (5) tahun agar perancangan strategis sistem informasi dapat diimplementasikan maksimal

\section{SARAN}

a. Saran untuk penelitian selanjutnya adalah perencanaan strategis sistem informasi dapat dilakukan dengan metodologi yang berbeda sehingga didapatkan hasil yang dapat menjadi perbandingan ataupun referensi; Sistem informasi yang diajukan dalam penelitian ini dapat dibuat hingga bentuk portofolio pada penelitian selanjutnya. 
b. Untuk implementasi layanan sistem informasi diperlukan dukungan dari semua pihak yang berhubungan dengan STIKOM Artha Buana Kupang.

c. Implementasi sistem informasi yang akan di terapkan sebaiknya STIKOM Artha Buana Kupang menyiapkan infrastruktur organisasi, sumber daya manusia yang akan menggunakan sistem informasi yang telah dibangun.

\section{DAFTAR PUSTAKA}

[1] Jogiyanto, H. M., 2005, Sistem Informasi Strategik Untuk Keunggulan Kompetitif, II, Andi, Yogyakarta.

[2] Fardani, R, L dan Nalawati, E, R., (2013), Perencanaan Strategis Sistem Informasi Berbasis Zachman Framework Pada Disnakertrans Provinsi Jawa Barat Seminar Nasional Sistem Informasi Indonesia (SEISINDO), 2 - 4 Desember 2013

[3] Sucipto dan Jamilah K., 2015, Perancangan Sistem Informasi Strategis Balai Desa Gadungan Untuk Integrasi Sistem Informasi Publikasi, seminar nasional teknologi informasi dan multimedia STMIK Amikom 2015

[4] Sholihah, Ina W, Utami, E, Henderi, 2015, Perencanaan Strategis Sistem Informasi Untuk Meningkatkan Keunggulan Kompetitif Sekolah Islam Terpadu, Citec Journal, Vol. 2, No. 4, Agustus 2015 - Oktober 2015 ISSN: 2460-4259.

[5] Heriadi, Agustono, M.Suyanto, Sudarmawan., (2014). Perencanaan Strategis Sistem Informasi STMIK Cahaya Surya Kediri, Citec Journal, Vol. 1, No. 1, November 2013 Januari 2014 ISSN: 2354-5771

[6] Ward, J., Peppard, J., 2002, Strategic Planning For Information Systems, Third Edition, John Willey \& Sons, Inggris.

[7] Martin, J. 1990. Information Engineering (Book II, Planning and Analysis). PrenticeHall.

[8] Suwarno,1996, Manajemen Strategik Konsep dan Kasus, edisi revisi, UPP AMP YKPN, Yogyakarta.

[9] http://tekno.liputan6.com/read/2900003/deretan-teknologi-ini-bakal-jadi-tren-di-tahun2017 diakses tgl 29 Maret 2017. 